\title{
La judicialización del derecho a la libre determinación de los pueblos originarios de México: la elección municipal bajo sistemas normativos internos en Oxchuc, Chiapas
}

The judicialization of the right to self-determination of the native peoples of Mexico: the municipal election under internal regulatory systems in Oxchuc, Chiapas

\section{Manuel Gustavo Ocampo Muñoa}

Doctor en Derecho

Investigador del Instituto de Investigaciones Jurídicas de la Universidad Autónoma de Chiapas, México Correo electrónico: manuel.ocampo@iij-unach.mx

https://orcid.org/0000-0002-4265-4761

\section{Cómo citar este artículo:}

Ocampo, M. G. (2020). La judicialización del derecho a la libre determinación de los pueblos originarios de México: la elección municipal bajo sistemas normativos internos en Oxchuc, Chiapas. Revista de la Facultad de Derecho y Ciencias Políticas, 50 (133), pp. 386-411.

doi: http://dx.doi.org/10.18566/rfdcp.v50n133.a08

Recibido: 03 de noviembre de 2019.

Aprobado: 03 de junio de 2020 


\section{Resumen}

El derecho a la libre determinación en materia política de los pueblos originarios de México, aun cuando se encuentra reconocido en el artículo 2 de la Constitución Política de los Estados Unidos Mexicanos (2020), debe judicializarse para su ejercicio. En el Derecho constitucional de las entidades federativas de México, si bien es cierto se les reconocen derechos colectivos, no existen leyes de desarrollo constitucional que refieran a los procedimientos a seguir, en caso de que la Asamblea comunitaria de un municipio de mayoría indígena decida elegir a sus autoridades municipales conforme a sus sistemas normativos propios. Ese vacío procesal del sistema electoral mexicano impacta en el ejercicio del derecho colectivo que tienen los pueblos originarios de decidir su destino en materia electoral municipal respetando las reglas constitucionales. Para demostrar lo anterior se hace un análisis del contexto político y jurídico del municipio indígena de Oxchuc-Chiapas, que impulsó la judicialización de ese derecho colectivo y culminó con la celebración de elecciones bajo sistemas normativos propios el 21 de abril del 2019.

\section{Palabras clave}

Derecho constitucional, derecho electoral, derechos políticos, política, pluralismo jurídico, interculturalidad.

\section{Abstrac}

The right to self-determination in political matters of the native peoples of Mexico, even when recognized in Article 2 of the Constitución Política de Los Estados Unidos Mexicanos (Political Constitution of the United Mexican States) (2020), must be judicialized for its exercise. In the constitutional law of the federal entities of Mexico, even if collective rights are recognized, there are no constitutionally developed laws that refer to the due procedures, in the case that the Asamblea Comunitaria (Communal Assembly) of a municipality with an indigenous majority decides to elect their municipal authorities in accordance with their own regulatory systems. This procedural gap in the Mexican electoral system impacts the exercise of the collective right that the native peoples have of deciding their destiny regarding municipal electoral matters while respecting constitutional rules. To demonstrate the aforementioned, an analysis is made of the political and legal context of the indigenous municipality of Oxchuc-Chiapas, which caused the judicialization of the mentioned collective right and ended with the holding of elections under its own regulatory systems on April 21, 2019.

\section{Keywords}

Constitutional law, electoral law, political rights, politics, legal pluralism, interculturality. 


\section{Introducción}

El derecho a la libre determinación en materia política de los pueblos originarios de México, si bien se encuentra reconocido en lo constitucional, para su ejercicio debe judicializarse.

En ese escenario, el Tribunal Electoral del Poder Judicial de la FederaciónTEPJF ha sido quien asume la responsabilidad de construir y reconocer, mediante sus resoluciones y criterios, la existencia de un derecho electoral indígena. Este se integra por el conjunto de leyes, procedimientos y sistemas propios vigentes, que rigen el nombramiento de las diversas autoridades comunitarias y se constituye como alternativa para la solución de conflictos en materia electoral en esos contextos.

EI TEPJF vincula a las autoridades de gestión electoral a realizar la verificación de la existencia de un sistema normativo interno en los municipios que han reclamado su derecho a realizar elecciones bajo esa condición y a corroborar, mediante una consulta, si es realmente el deseo de la mayoría el cambio de sistema electoral. Una vez satisfechos estos criterios se autoriza la celebración de la elección bajo la supervisión del organismo electoral local.

Para demostrar lo anterior se hace un análisis del contexto político y jurídico del municipio indígena de Oxchuc-Chiapas, donde se impulsó la judicialización de ese derecho colectivo y culminó con la celebración de elecciones bajo sistemas normativos propios el 21 de abril del 2019.

Con fines didácticos este trabajo se divide en siete apartados: el primero de ellos destinado a esta introducción y los restantes al desarrollo del tema, conclusiones y bibliografía empleada.

En el marco teórico, se establecen los conceptos centrales utilizados en este documento y cuyo dominio facilita su entendimiento.

En el discurso intercultural del sistema electoral mexicano se establece la manera en que el sistema electoral mexicano atiende los temas relacionados con el derecho electoral indígena.

Bajo la denominación la judicialización del derecho electoral indígena frente a la crisis política en Oxchuc, se hace una descripción de la problemática política suscitada en el municipio indígena de Oxchuc-Chiapas, con la finalidad 
de demostrar que los pueblos originarios bajo condiciones especiales suelen tomar decisiones que parecen contraponerse al sistema jurídico hegemónico. Sin embargo, estas determinaciones las toman alegando el derecho colectivo a la toma de decisiones en materia política.

En la interlegalidad como resultado del ejercicio del derecho a la libre determinación en Oxchuc se plantean y analizan las reglas utilizadas en la elección del 13 de abril del 2019, que fueron construidas por la Asamblea comunitaria.

\section{Marco teórico}

Con la intención de dar más elementos para el debate, a continuación se establecen los conceptos clave que se utilizan para sostener el argumento central. El término interculturalidad hace referencia a las relaciones que existen entre los diversos grupos humanos que conforman una sociedad dada y que en la actualidad se usa como un término más complejo y polisémico, vinculado a las relaciones que existen dentro de la sociedad entre diversas constelaciones de mayoría-minoría, que se definen no sólo en términos de cultura sino en términos de etnicidad, lengua, denominación religiosa y/o nacionalidad (Dietz, 2017, p).

La interculturalidad es entendida como un derecho que faculta al individuo a vivir en un entorno de riqueza cultural, conocimiento recíproco y respeto mutuo entre personas y grupos de distintos orígenes, lenguas, religiones y culturas. Se manifiesta en lo jurídico como un discurso de diferentes acentos continentales, nacionales y regionales, así como en los sesgos disciplinarios de sus protagonistas: las identidades étnicas, las dinámicas migratorias y la diversidad cultural (Romero, 2011).

En lo que atañe al mundo normativo, la interculturalidad parte del respeto a la autonomía de las formas de derecho propio de cada cultura. Autonomía que sólo podría tener como límites los provenientes de un eventual consenso de las culturas involucradas, nunca la imposición de valores que no necesariamente son compartidos con la misma fuerza o voluntad.

El pluralismo jurídico aparece con la idea de que el Estado no es el único centro productor de normas jurídicas; se le considera un fenómeno de coexistencia de normas que reclaman obediencia en un mismo territorio y que 
pertenecen a sistemas normativos distintos. Además, se asocia el pluralismo jurídico con la existencia de sistemas alternativos, siendo la característica más importante de estos sistemas normativos el hecho de estar organizados en torno a una norma de reconocimiento (Correas, 1994).

Una posición innovadora respecto del pluralismo jurídico es aquella que concibe al derecho como un producto de la constante intersección de diferentes órdenes legales, consecuencia que se vive en una época de porosidad legal, de múltiples órdenes normativos que regulan al mismo tiempo las mismas conductas (Santos, 1987).

Desde la interlegalidad un sistema normativo interno como el de los pueblos originarios reúne poder, derecho y conocimiento, creando un todo armónico dentro de una sociedad determinada. Es una intersección de diferentes órdenes legales en la que existe una relación entre el pluralismo jurídico y el pluralismo cultural, estos son más dicientes en sociedades que han pasado por procesos de colonización como el caso de las latinoamericanas, debido a que en un espacio determinado se hallan distintas culturas con su propia teoría del Derecho y pluralismo jurídico, con sus respectivas prácticas jurídicas o regulativas (Santos, 2002).

Ahora bien, un sistema normativo se identifica como el conjunto de normas jurídicas orales y consuetudinarias que los pueblos y comunidades indígenas asumen como válidas y obligatorias, utilizan para regular su vida pública y resolver los conflictos. Desde la concepción defendida de la identidad indígena como relacional, contextual y dinámica, el orden jurídico indígena se define como lo que los propios indígenas reconocen como su gobierno, justicia, sus autoridades, sus normas, sus procedimientos e instituciones (Yrigoyen, 1999).

Los sistemas normativos de las comunidades indígenas están constituidos por un conjunto de normas, instituciones y procedimientos que sirven para su integración y organización social, son parte del campo jurídico y como tales deben ser entendidos en tanto derecho propio. Este derecho propio o derecho indígena es producto de la transformación histórica de sus comunidades y pueblos, en su relación con el Estado mexicano, donde están inmersos y en el que han participado de manera subalterna.

Se puede afirmar que existen tantos sistemas normativos diferenciados como pueblos y comunidades coexistiendo en el territorio nacional. Los procesos que utilizan para la designación de sus autoridades revelan la cosmovisión, los 
saberes diversos y los valores de cada comunidad. Dentro de los sistemas y formas de gobierno indígena se encuentran los sistemas de cargos o servicios, la organización comunitaria en barrios, los consejos de ancianos y el tequio o faena, estos se describen a continuación de manera breve.

En la mayor parte de las comunidades latinoamericanas que gozan de raíces prehispánicas se puede notar la práctica de los Usos y Costumbres. Estos tienen su antecedente más cercano en el sistema de cargos, que son oficios religiosos ocupados con base en una rotación entre los hombres de una comunidad (Korsbaek, 1996).

En los sistemas de cargos — también conocidos como de servicios- las autoridades son nombradas por la Asamblea hoy día en la mayoría de los casos. Comúnmente los cargos son obligatorios desde los dieciocho años o antes. Si la persona se casa y forma así una unidad familiar independiente de la de sus padres, o después si sale a estudiar, pues al regresar de la universidad, debe ponerse a las órdenes de las autoridades y presentarse en la Asamblea, quien le asignará su primer cargo.

Los cargos se desempeñan en nombre de la familia y su cumplimiento da la posibilidad a todas las personas que la integran de gozar de los derechos comunitarios. A manera de ejemplo, en la región huichola los cargos de jicareros tienen la responsabilidad de cuidar la jícara de una entidad ancestro comunal por un periodo de cinco años y asistir obligatoriamente a las fiestas grandes, que se realizan en el centro ceremonial (Fajardo, 2010).

En comunidades tzeltales de Chiapas, el sistema de cargos recae en la unidad familiar y en la complementariedad necesaria dentro de la pareja para poder realizarlos, pues no son remunerados e implican tener que dejar las otras actividades familiares y económicas para cumplirlos. Todo esto con el fin de cumplir bien con la comunidad, tener prestigio dentro de ella y hacer posible el funcionamiento del gobierno comunitario.

Las formas de representación de la autoridad se reconocen en el sistema de cargos: un sistema político y otro religioso. Quien acepta un cargo deja su paraje y su milpa durante un año para residir temporalmente en la cabecera municipal. Esto significará el endeudamiento para subsistir durante ese tiempo y para sufragar los gastos que le representa el cargo (Gómez, 2004). 
La institución indígena que recibe el nombre de tequio o faena es el trabajo colectivo realizado para el bien común, es un reflejo de valores y principios propios que sustentan una visión colectiva de la vida y del bienestar. Es el trabajo comunal presentado como un deber de cada uno en beneficio de la comunidad actual y también de la futura. Se piensan en las mejoras como miembros de un pueblo y siempre se refieren al interés colectivo (Cordero, 2009).

Ahora bien, el control que tienen los pueblos originarios de su propio destino y de elegir bajo su propio sistema a la autoridad política, son elementos esenciales de las normas internacionales consuetudinarias. Estas se toman de referencia para efectos de la judicialización de ese derecho en el sistema electoral mexicano (Anaya, 2004). Lo anterior se advierte en el contenido del discurso intercultural de dicho sistema.

De igual manera, resulta relevante el hecho de que algunos pueblos originarios de Chiapas aprovechen las vías de acceso diseñadas para la protección de derechos humanos y generen una visión propia de su realidad, que influya en el diseño de las nuevas políticas públicas con la intención de enfrentar los retos de la gestión de la diversidad cultural y el aseguramiento de sus derechos (Anaya, 2011). Tal es el caso del Movimiento en Defensa de la Vida y el Territorio- Modevite que agrupa hombres y mujeres tseltales, tsotsiles y choles de municipios y comunidades de la zona de los altos y selva en el Estado de Chiapas en México (Huixtán, Oxchuc, Ocosingo, Altamirano, Chilón, Sitalá, Yajalón, Tumbala, Tenejapa, Cancuc y el ejido Candelaria municipio de San Cristóbal); cuyo objetivo es la defensa de la vida y el territorio, además, exigen a los tres niveles de gobierno el respeto y cuidado de las riquezas naturales en las que esos pueblos originarios habitan.

Cabe mencionar que, muchos de los ayuntamientos constituidos en municipios de mayoría indígena en el mencionado Estado del sureste mexicano carecen de aceptación de buena parte del colectivo, pues no tienen legitimación material. Esto se debe en buena medida a que surgen de procesos electorales constitucionales afectados por el engaño y el clientelismo, como fue el caso del local ordinario 2014-2015 que incluyó el incumplimiento de la obligación por parte de los partidos políticos de acatar la cuota de género ordenada por la ley electoral y, posteriormente, la destitución de los consejeros y consejeras del órgano de gestión electoral por actos de corrupción (Ocampo, 2018). 


\section{El discurso intercultural del sistema electoral mexicano}

El punto de partida del respeto al ejercicio de los derechos políticoelectorales radica en la percepción que tengan las autoridades involucradas de la diversidad cultural dentro del sistema electoral, siendo una herramienta fundamental el discurso intercultural que promuevan, es por esto que se hacen las siguientes precisiones.

La interculturalidad en tanto filosofía tiene como punto de partida el reconocimiento del derecho a vivir en un entorno de riqueza cultural, conocimiento recíproco y respeto mutuo entre personas y grupos de distintos orígenes, lenguas, religiones y culturas (Dietz, 2011).

Por consiguiente, es posible plantear como parte de la política pública de una institución, dependencia pública o privada, un discurso intercultural adecuado al contexto social, económico, cultural, jurídico o político.

Para efectos de este trabajo se denomina discurso intercultural la manera en que el Instituto Nacional Electoral- INE y el TEPJF interpretan el respeto a las diferencias, los saberes diversos y las identidades de los pueblos originarios de México en materia electoral. Esto se refleja en sus estrategias, criterios y planes de trabajo.

Desde la gestión electoral, el INE refiere a la interculturalidad como parte de los diez componentes que conforman su Estrategia Nacional de Cultura Cívica-Encivica, lanzada en 2017. Además, se utiliza el término para indicar la interrelación entre grupos y personas con culturas distintas; que se sustenta normativamente en las formas del Estado multicultural, también implica que la relación entre grupos y personas con culturas distintas se da desde planos de igualdad, lo que a su vez involucra la aceptación de todas las culturas y las personas como igualmente dignas y valiosas (INE, 2016).

Con respecto al TEPJF se advierte respeto a la cosmovisión y a los sistemas normativos internos de los pueblos y comunidades originarias. En algunas Sentencias de sus salas regionales y por supuesto de la Sala Superior, donde se han generado tesis y jurisprudencias que han sentado las bases de lo que se ha denominado Derecho electoral indígena. Juzgar con perspectiva intercultural en materia electoral se convirtió en una exigencia a partir de la sentencia SUP- 
JDC-1011/2013 (2013) y acumulado que estableció el criterio según el cual en los casos de derechos relacionados con los derechos de los pueblos indígenas era necesario valorar las circunstancias en las que surgen, para definir claramente los límites de la controversia jurídica puesta a consideración de las autoridades electorales y resolverla desde una perspectiva intercultural. Esto a fin de atender tanto los principios o valores constitucionales y convencionales, como los valores y principios de la comunidad (TEPJF, 2017).

Algunos casos relevantes y emblemáticos relacionados con el ejercicio del derecho a la libre determinación en México en el que se advierte la visión intercultural del TEPJF son: el de Cherán en el Estado de Michoacán y Ayutla de los libres en Guerrero, estos establecen una ruta en la defensa de ese derecho colectivo.

En el Caso de Cheran- Michoacán, el 26 de agosto de 2011 la citada comunidad presentó una solicitud al Instituto Electoral del Estado de Michoacán-IEM suscrita por 942 personas, donde pidieron que fuera respetado el derecho a decidir y elegir el nombramiento de sus autoridades en ese municipio, conforme a sus usos y costumbres (IEM , 2012).

El 9 de septiembre de 2011, el IEM emitió el Acuerdo CG-38/2011 (IEM, 2011) argumentando carecer de atribuciones para determinar respecto a la petición de dichos ciudadanos, por esto el 15 de septiembre de 2011 los ciudadanos actores promovieron ante el Tepjf la protección de los derechos político-electorales del ciudadano.

El 2 de noviembre del 2011 la Sala Superior del Tepjf reconoció en el expediente SUP-JDC-9167/2011 (2011) el derecho de los integrantes de la comunidad indígena del municipio de Cherán para elegir autoridades por medio de sus prácticas tradicionales. El caso constituye el inicio de una nueva etapa para los pueblos indígenas del Estado de Michoacán en cuanto al derecho a la libre determinación.

A partir de esta resolución se establece que para la demostración de la calidad de comunidad indígena basta la simple auto- adscripción individual o colectiva, sin que pudiera ser objeto de refutación a través de los medios de prueba ordinarios. Se consideró que el Consejo General del IEM, con la emisión del acto reclamado, no proveyó en la esfera administrativa las medidas necesarias para el respeto, promoción y protección de los derechos fundamentales de las comunidades indígenas en el Estado, pese a la solicitud 
expresa de la comunidad indígena de Cherán, de este modo no cumplió con las obligaciones protección que, en su calidad de autoridad, le impone el artículo 1 de la Constitución Federal (2020)

Sobre tales insuficiencias, se razonó que la falta de actividad del órgano legislativo local, así como de la autoridad electoral estatal no podían traducirse, en forma alguna, como obstáculo para el ejercicio pleno de los derechos reconocidos constitucionalmente a las comunidades indígenas en el Estado. Se reconoce el derecho a la consulta de la comunidad indígena de Cherán en la configuración de las decisiones, respetando siempre el consentimiento libre, previo e informado de sus integrantes.

En el caso Ayutla de los libres en el Estado de Guerrero, la demanda de elecciones por usos y costumbres inició el 26 de junio de 2014, cuando 61 autoridades comunitarias solicitaron al Instituto Electoral y de Participación Ciudadana del Estado de Guerrero-IEPC Guerrero que el proceso electoral de ayuntamiento, cuya jornada electoral se llevaría a cabo el 7 de junio de 2015, se realizara mediante sistemas normativos internos.

Sin embargo, ante la falta de respuesta de parte del IEPC Guerrero, acudieron a la Sala Superior del Tepjf y lograron que mediante Sentencia se ordenara realizar una consulta en la que los ciudadanos decidirían si estaban de acuerdo con utilizar ese sistema electoral. La consulta se llevó a cabo en octubre de 2015 y en ella la mayoría votó a favor y quedó establecido legalmente que en el 2018 se realizarían las elecciones para presidente municipal por el sistema normativo propio. El caso de Ayutla de los Libres es, sin duda, un precedente muy importante por la manera en que se desarrolló el procedimiento de consulta indígena.

También, como parte de ese discurso intercultural, el Tepjf ha diseñado guías, manuales y otros documentos con la intención de promover la defensa y la adecuada protección de los derechos políticos de la población indígena. Tal es el caso de la guía de actuación para juzgadores en materia de derecho electoral indígena (TEPJF, 2017).

Aunado a lo anterior, se deja en claro la intención de avanzar en el tema del acercamiento a las denominadas minorías representativas y se crea la Defensoría Pública Electoral para Pueblos y Comunidades indígenas como un órgano auxiliar de la Comisión de Administración del Tepjf, con independencia técnica y autonomía operativa, encargada de prestar gratuitamente los 
servicios de defensa y asesoría electorales a favor de los pueblos, comunidades indígenas y personas que los integren.

Cabe destacar que la mencionada defensoría presta sus servicios de dos formas: asesoría electoral, mediante la orientación, guía o instrucción técnica sobre la naturaleza, contenido y alcances de los derechos político-electorales, establecidos a favor de los pueblos, comunidades indígenas o alguna de las personas que los integren y por medio de la defensa electoral, es decir, la representación y/o defensa de los derechos político electorales ante las Salas del Tepjf El compromiso de las defensoras y los defensores en general es pugnar porque las autoridades rebasen las visiones formalistas y respondan, desde un lenguaje de derechos, a la falta de acceso de los indígenas a la justicia, entre otras cosas, al exigir que se provea de lo necesario para que la persona o personas involucradas comprendan y se hagan comprender dentro del juicio, además, que sean consideradas sus condiciones, contextos y necesidades particulares.

En los últimos años el Tepjf promueve la justicia abierta como estrategia de cercanía a la ciudadanía y atención a las demandas sociales en materia electoral, por lo que en materia procesal electoral ha diseñado figuras jurídicas como la suplencia de la queja para los pobladores indígenas.

De igual manera se autoriza tutela especial en aquellos medios de impugnación que lo permiten, ordena pruebas antropológicas para que sean los expertos quienes digan si en cada comunidad procede la implementación de la universalidad del sufragio o se está rompiendo el sistema normativo.

Finalmente, la Sala Superior ha resuelto en diferentes asuntos que involucran al Consejo General del INE y a los pueblos originarios que dicho órgano de gestión electoral debe dar respuesta inmediata, como en el caso de la petición de un grupo de ciudadanos para instalar una casilla especial de votación para los habitantes -al menos 246 indígenas tsotsiles-, que se vieron obligados a desplazarse por hechos violentos que ocurrieron en mayo de 2016, quienes para salvaguardar su vida viven en un campamento desde febrero 2017.

Las tareas y estrategias antes descritas son, en general, buenas prácticas que pueden acercar a la ciudadanía y a las autoridades electorales. Al parecer existe voluntad política de quienes intervienen en el proceso electoral, se advierte que entienden la interculturalidad y hacen esfuerzos de acercamiento a esos colectivos. 
Sin embargo, queda mucho camino por recorrer, no es suficiente con la existencia del marco jurídico de protección a los derechos político electorales de las comunidades indígenas, se requiere la materialización de todas las acciones positivas.

No debe perderse de vista que en cada proceso electoral surgen nuevas discusiones y actos de corrupción que involucran a los pueblos originarios, lo que refleja la necesidad de resolver problemas sociales de fondo. Es la propia ciudadanía de cada pueblo o comunidad la que conoce en realidad los desafíos locales; incorporar como defensores y defensoras en los tribunales a personas de origen indígena no es suficiente se requiere incorporarlos en la labor jurisdiccional como secretarios de acuerdos, proyectistas y a futuro como magistradas y magistrados electorales es una buena alternativa de acercamiento y de participación jurídico política, que debe incluirse en la política pública de justicia electoral abierta en escenarios de diversidad cultural.

\section{La judicialización del derecho electoral indígena frente a la crisis política en Oxchuc}

En el municipio indígena de Oxchuc, ubicado en los altos de Chiapas, con población de mayoría tzeltal pero con presencia también en algunas de sus comunidades de tzotziles, existen procedimientos internos bien definidos para elegir a sus autoridades. Hasta antes de la aparición de los partidos políticos, estos se utilizaban eficientemente y con su ejercicio se mantuvo la paz en los pueblos y comunidades. Esto debido principalmente a que se trataba de un sistema de elección incluyente, que tomaba en consideración a las autoridades tradicionales, a las comunidades, a los principales y repartía el poder en la conformación de la autoridad municipal.

Desafortunadamente al momento de incorporarse el derecho a la libre determinación en materia política como derecho colectivo de los pueblos indígenas en el ordenamiento constitucional ganaron el reconocimiento estatal; pero perdieron la unidad dentro de la comunidad y, en el caso del Estado mexicano, si bien es cierto que su sistema hegemónico cedió un poco en materia electoral; no obstante, mantiene la exclusividad en la solución de conflictos a través del Tepjf, quien tiene la última palabra. 
Por tanto, para efectos de este trabajo resulta relevante analizar la postura que asume el sistema hegemónico en la resolución de los conflictos político-electorales en Oxchuc, pues esa judicialización del derecho electoral indígena constituye el referente para el pluralismo jurídico, que se construye actualmente en Chiapas. Aunado a que permite establecer la coexistencia entre los sistemas jurídicos estatal y originario.

El primero de los asuntos está relacionado con el proceso electoral local de 2015, fue el Juicio de inconformidad promovido el 22 de junio de 2015 por Miguel Santiz Gómez en contra de la aprobación del registro de María Gloria Sánchez Gómez, como candidata a Presidenta Municipal del Municipio de Oxchuc, Chiapas por el Partido Verde Ecologista de México, el Instituto de Elecciones y Participación Ciudadana del Estado de Chiapas- IEPC Chiapas mediante Acuerdo IEPC/CG/A-071/2015 (2015) de 15 de junio de 2015 emitido por el Consejo General. ${ }^{1}$

Sin duda, las actuaciones del Tepjf que son trascendentales con respecto al actual conflicto político de Oxchuc se documentan en los juicios para la protección de los derechos político electorales del ciudadano, promovidos por Amalia Sánchez Gómez, Elia Santiz López, Miguel Gómez Hernández y Mario Gómez Méndez respectivamente, ostentándose como primera y tercera regidoras, primer síndico y segundo regidor del Ayuntamiento de Oxchuc-Chiapas, contra la Sentencia de 9 de mayo del 2016, emitida por el Tribunal Electoral del Estado de Chiapas (TEECH) en los expedientes TEECH/ JDC/010/2016 (2016) y acumulados. ${ }^{2}$

El SUP-JDC-1697/2016 (2016) promovido por Alicia Santiz Gómez, Mercedes Gómez Sánchez y Sara Santiz López, quienes combaten el Decreto 174 (2016) de 2 de marzo de 2016 emitido por el Congreso del referido Estado, por el que fueron sustituidas en el cargo de regidoras por el principio de representación proporcional en el citado ayuntamiento, así como la omisión del presidente municipal de tomarles protesta para desempeñar el cargo precisado.

1 La sentencia del Juicio de inconformidad TEECH/JI/032/2015 (2015) promovido por Miguel Santiz Gómez, puede consultarse en: http://www.tribunalelectoralchiapas.gob.mx/sentencias/TEECHJl-032-2015.pdf

2 La sentencia de los juicios para la protección de los derechos político-electorales del ciudadano expedientes: SUP-JDC-1690/2016 (2016) y acumulados promovidos por Amalia Sánchez Gómez y otros puede consultarse en: https://portal.te.gob.mx/colecciones/sentencias/html/SUP/2016/JDC/ SUP-JDC-01690-2016.htm 
Finalmente, la controversia planteada en el juicio SUP-JDC-1756/2016 (2016) el 17 de agosto de 2016 promovido por María Gloria Sánchez Gómez per saltum ante el Tepjf, mediante demanda en la que se advierte que el 4 de febrero del 2016, la referida ciudadana presentó ante el Congreso del Estado de Chiapas licencia al cargo de Presidenta Municipal de Oxchuc, la cual fue calificada como renuncia por el Congreso del Estado mediante Decreto 161(2016) de once de febrero.

El 24 de junio presentó oficio dirigido al presidente de la Mesa Directiva del citado órgano legislativo, en que solicitó su reincorporación al cargo. El 14 de julio presentó un diverso escrito ante la misma autoridad, en que solicitó que a la brevedad se pronunciara sobre lo peticionado. El 2 de agosto le fue notificado el oficio 0327 suscrito por la secretaria de la Comisión Permanente del Congreso del Estado de Chiapas, en el cual le notificó que no era posible reincorporarla al cargo, toda vez que mediante Decreto 161(2016) su licencia fue calificada como renuncia.

Inconforme con lo anterior, el 8 de agosto presentó demanda de juicio para la protección de los derechos político-electorales del ciudadano ante el Teech; sin embargo, el 17 del mismo mes desistió para acudir per saltum ante la Sala Superior del Tepif.

Al entrar al estudio del asunto la Sala Superior consideró válido afirmar que, con motivo de la elección efectuada en julio de 2015, se desató un conflicto social y político que derivó en diversos hechos violentos que han tenido repercusión en todo el municipio, lo que llevó a María Gloria Sánchez Gómez a presentar licencia por tiempo indefinido ante el Congreso del Estado el día 4 de febrero de este año. A juicio de la Sala Superior, es evidente que las presiones y la violencia política probada puso a la Presidenta Municipal en una situación de mayor vulnerabilidad que la orilló a presentar su licencia. Se acredita que, a lo largo de los primeros seis meses de ejercicio del Cabildo constitucionalmente electo, se presentaron situaciones de violencia, conflicto social y atentado contra el órgano de gobierno municipal. Estas impidieron el normal desarrollo de las funciones del Ayuntamiento, centrándose estas protestas en la destitución de María Gloria Sánchez Gómez en el cargo en la Presidencia Municipal.

En consecuencia, la autoridad judicial electoral tuvo como plenamente acreditado que la presidenta municipal renunció por presión, pues no existe controversia respecto de si existió un contexto de confrontación y hechos 
violentos desde la elección de julio de 2015, por lo que existe justificación para invalidar su renuncia al cargo de Presidenta Municipal y la solicitud de licencia indefinida inducida por error y por violencia para presentarla, dado que el vicio de la voluntad que originó la solicitud de licencia no ha desaparecido sino que conforme a las constancias en autos, se ha intensificado la violencia, siendo conforme a Derecho revocar el Decreto 161 de 11 de febrero del 2016, emitido por el Congreso del Estado de Chiapas, así como el oficio 0327 emitido por la Secretaria de la Comisión Permanente del propio Congreso local en los que negó a María Gloria Sánchez Gómez su reincorporación al cargo de Presidenta Municipal.

Aunque no de inmediato, debido a la inconformidad de un buen número de comunidades de Oxchuc, se cumplió la sentencia. No obstante, los movimientos de protesta continuaron.

El 11 noviembre del 2016, la organización denominada Comisión Permanente por la Paz y Justicia del Municipio de Oxchuc-Chiapas presentó un escrito ante el IEPC, para solicitar autorización y celebrar la elección de sus autoridades municipales, a través de su sistema normativo propio.

En enero de 2017, aproximadamente 28 mil pobladores de Oxchuc, encabezados por autoridades comunitarias y tradicionales firmaron una petición dirigida al IEPC para solicitar que las elecciones municipales del proceso 2018 se realizaran sin la participación de partidos políticos, es decir, mediante el sistema normativo interno.

Con fecha 10 de febrero de 2017 la propuesta de la Comisión Permanente de Participación Ciudadana del Consejo General del IEPC se emite el acuerdo IEPC/CG-005/2017 (2017), mediante el cual se determinó que no son procedentes las peticiones planteadas por la Comisión Permanente por la Paz y Justicia del Municipio de Oxchuc-Chiapas, de celebrar elecciones a través del sistema normativo de usos y costumbres del municipio de Oxchuc. Ante la incompetencia que argumentó el IEPC para autorizar elecciones, pues eso era competencia del legislado, la comisión permanente por la paz y la justicia en Oxchuc promovió juicio para la protección de los derechos políticos electorales del ciudadano.

El 8 de marzo de 2017 se presentaron por un grupo de ciudadanos y organizaciones escritos de promoción de juicios para la protección de derechos políticos electorales del ciudadano ante la Sala Superior del Tepjf, 
vía per saltum. El 4 de abril de 2017 dicha autoridad determinó declarar improcedentes los juicios ciudadanos y en consecuencia ordenó reencauzarlos al Teech para que resuelva.

El 28 de junio del 2017 el Teech emitió en el expediente Teech/ JDC/019/2017(2017) y sus acumulados ${ }^{3}$, sentencia definitiva en la que ordena al IEPC ejecutar diversas acciones para determinar la viabilidad de la implementación de los usos y costumbres en este municipio, para que puedan elegir a sus representantes dentro del Ayuntamiento municipal, sin participación de partidos políticos.

No obstante lo anterior, la preparación del proceso electoral ordinario 2018 exigía mayor atención y el Congreso del Estado de Chiapas emitió el 2 de abril de ese año, un decreto que autorizaba al IEPC a modificar las fechas y procedimientos del mismo en lo tocante a Oxchuc, hasta que concluyera el periodo de consulta. En consecuencia no se realizaron elecciones locales en el municipio.

Una vez que se terminó de manera oficial el mencionado proceso electoral local en lo concerniente a la participación del IEPC, se reanudaron los trámites y el 19 de septiembre recibió el dictamen antropológico denominado sistema normativo indígena para la designación de autoridades en el municipio de Santo Tomás-Oxchuc, realizado por el Instituto Nacional de Antropología e Historia (INAH). Este concluyó que el sistema normativo interno que regula las formas de gobierno indígena en el municipio de Oxchuc mantiene su vigencia y particularidades. Los cambios experimentados en este sistema de cargos no son prueba de su debilitamiento sino más bien de la capacidad de adaptación a las nuevas condiciones y circunstancias políticas, características que lo hacen dinámico y permiten su coexistencia con el sistema político nacional. Si bien el sistema normativo interno no es discordante con el marco constitucional de los derechos humanos, requiere adaptarse a fin de fortalecer la incorporación de las mujeres y los jóvenes.

Una vez recibido el dictamen se procedió a organizar la consulta para que las y los ciudadanos del municipio decidieran sobre qué sistema elegirían a sus autoridades municipales: si por partidos políticos o por usos y costumbres.

3 La sentencia de los juicios para la protección de los derechos político electorales del ciudadano expedientes: TEECH/JDC/019/2017 (2017) y acumulados promovidos por Sara Gómez Méndez y otros puede consultarse en http://www.tribunalelectoralchiapas.gob.mx/sentencias/TEECHJDC-019-2017.pdf 
Bajo los estándares internacionales de consentimiento libre, previo, informado y de buena fe, fueron convocadas las Asambleas de consulta indígena en las 120 comunidades de Oxchuc (Burguete, 2019).

El porcentaje de participación alcanzado fue de 97\%, debido a que en las localidades El Pozo, Navil, Stenlej Akil y Cruz Akilja, no obtuvieron el quórum requerido en las tres convocatorias para celebrar su Asamblea Comunitaria de Consulta Indígena. Es por esto que conforme a los lineamientos, no fueron considerados para la obtención del resultado y su participación dentro de la consulta equivale al 3\%. Cabe mencionar que el listado nominal del municipio es de 35 mil 780 personas.

El 5 de enero de 2019 se celebró la Asamblea plenaria de resultados, donde la ciudadanía de Oxchuc decidió por el sistema normativo interno para elegir a sus autoridades municipales.

De acuerdo con los resultados, fueron 72 localidades que optaron por el sistema de usos y costumbres, que en su conjunto representa el 62\%; mientras que 44 localidades decidieron por partidos políticos, lo que representa el 38\% en las 116 localidades donde se realizaron Asambleas Comunitarias de Consulta Indígena. El objetivo de la Asamblea fue dar a conocer a la ciudadanía del municipio, a través de sus representantes, el resultado de su voluntad, plasmada en cada una de las actas de asamblea comunitaria de consulta celebradas, respecto del sistema de elección de sus autoridades municipales por el que optaron.

El 15 de enero del 2019 el Consejo General del IEPC declaró la validez de los resultados de la Asamblea Plenaria en sesión pública. En virtud de lo anterior el Congreso del Estado emitió el Decreto 135 (2019) con fecha 23 de enero de 2019 por el que se faculta al IEPC para convocar, coadyuvar y, en su caso, organizar la elección de autoridades municipales del municipio de Oxchuc-Chiapas, así como calificar y expedir la constancia de mayoría a través del régimen de elección por sistema normativo interno.

En cumplimiento a lo anterior, el IEPC elaboró los lineamientos a seguir y calendarizó las actividades del proceso de elección de autoridades municipales en Oxchuc bajo el sistema normativo de usos y costumbres. Este comprendía la celebración de mesas de trabajo con la finalidad de elaborar la convocatoria e involucrar a los grupos de ciudadanos de Oxchuc, de tal forma que fueran 
ellos quienes establecieran los criterios del proceso electoral, las reglas y los perfiles de elegibilidad para determinar quiénes podrían ser candidatos y el procedimiento de elección.

Por Acuerdo IEPC/CG-A/007/2019 de fecha 11 de febrero de 2019 se aprobó la Convocatoria a la ciudadanía de este municipio para integrar la Asamblea General, que se constituye en la máxima autoridad de deliberación y toma de decisiones para la elección de autoridades municipales en Oxchuc. En cumplimiento al Decreto 135(2019) del Congreso del Estado, fue convocada por el presidente del Concejo Municipal de Oxchuc.

El domingo 24 de febrero de 2019 se celebró y como parte del orden del día, se verificó el quórum legal para instalar la Asamblea, consistente en por lo menos el 50\% más uno del total de las 120 localidades-comunidades que fueron consultadas. Solamente representantes de nueve localidades no asistieron: Cruzaquilja, San Marcos, Cholol, Santa Teresa La Reforma, Tekmaxtik, Saklumilja, Jutuba, El Porvenir, Newitz, y Chapultepec. Por lo anterior quedó formalmente instalada la Asamblea general, con la asistencia de representantes propietarios de 111 localidades, de un total de 120 que integran el municipio. Cabe mencionar que dichos representantes fueron nombrados en las correspondientes Asambleas Comunitarias que se realizaron en cada localidad, del 13 al 19 de febrero del 2019.

Ese mismo día, cumpliendo con el principio de paridad, la Asamblea General eligió a través del método de mano alzada a las y los integrantes de la Mesa de Debates, allí quedó como presidente el representante de la comunidad Santísima Trinidad y una representante de Bumilja como suplente. La Mesa de Debates tendrá como responsabilidad llevar el desarrollo de la Asamblea General, procurar acuerdos entre las y los representantes, levantar las actas respectivas, ser el enlace entre el Municipio y el IEPC y notificar a este último del cumplimiento de cada una de las etapas del proceso de elección.

Durante el desarrollo de la Asamblea General, por unanimidad manifestada a mano alzada, las y los representantes determinaron solicitar la coadyuvancia del IEPC en la elaboración de las reglas y, en su caso, la organización del proceso de elección (Burguete, 2019). 


\section{La interlegalidad como resultado del ejercicio del derecho a la libre determinación en Oxchuc}

Las reglas utilizadas en el proceso electoral de Oxchuc fueron elaboradas por la Asamblea General Permanente, se trata de un documento integrado por cuarenta normas, agrupadas en once temas que armonizan reglas vigentes décadas atrás con derechos contemporáneos. La intención fue recuperar las buenas prácticas de su derecho electoral y actualizarlas en un nuevo catálogo de normas. De acuerdo con lo pactado dichas propuestas fueron entregadas al IEPC el 19 de marzo del 2019 para su validación.

Una vez revisadas, el IEPC con fecha 29 del mismo mes y año emitió el Acuerdo del Consejo General por el que se validan las normas que regirán la elección de las autoridades municipales del municipio de Oxchuc. Chiapas, conforme su sistema normativo interno. Este documento contiene dos secciones, una relativa a los acuerdos de las cinco asambleas realizadas por la Asamblea General Permanente como acuerdos sobre sus reglas electorales, en ejercicio de su derecho al autogobierno y otra dirigida a las observaciones y sugerencias que el IEPC hace a las mismas, en cumplimiento al Decreto 135(2019).

Dentro de las nuevas reglas del sistema normativo electoral de Oxchuc destacan entre otras las relacionadas con los requisitos de elegibilidad, la creación de la comisión de mediación, la determinación de la figura de la autoridad municipal, el método de la lección, el respeto al principio de paridad, el modo honesto de vivir y la revocación de mandato.

En cuanto a la sección de requisitos de elegibilidad se estableció la limitación a las/los aspirantes a los cargos de no pertenecer al Estado eclesiástico ni ser ministro de algún culto religioso en el municipio. Norma que atiende el hecho de que más de la mitad de la población del municipio profesa hoy distintas religiones cristianas evangélicas y que años atrás los conflictos religiosos se vivieron de manera muy violenta, con miles de expulsados en los municipios indígenas.

Se crea una comisión de mediación y resolución de conflictos, que probablemente intente cumplir con una de las funciones del gobierno indígena que es la resolución de conflictos en procesos electorales, para establecer mediaciones. Esta nueva comisión quedó integrada con cuatro personas, con miras a cumplir con el principio de paridad de género: Dionisio Encinos Gómez, 
presidente; Rosa Morales López, secretaria; Daniel Gómez Santiz, primer vocal y Norma Araceli Santiz López, segunda vocal.

Un aspecto interesante fue la decisión de la Asamblea de refrendar como su forma de gobierno municipal el Ayuntamiento en los términos del artículo 115 de la Constitución Política de los Estados Unidos Mexicanos (2020), puesto que la sociedad civil protagonizó una lucha por recuperar su sistema electoral propio en un marco del ejercicio del derecho de autodeterminación indígena y no lo ejercitó respecto del diseño de un nuevo sistema de autoridades, que propiciara un gobierno propio.

Lo anterior marca una diferencia crucial con los procesos ocurridos en Cherán, Michoacán y en Ayutla de los Libres Guerrero. En estos municipios se establecieron Concejos de gobierno que sustituyeron a los Ayuntamientos, en Cherán el Concejo Mayor de Gobierno; mientras que Ayutla creo el Concejo Comunitario. Una razón de fondo para mantener al ayuntamiento quizá sea el diseño de las políticas fiscales y del sistema fiscal de las entidades federativas que privilegían esa forma de gobierno. A los concejos de gobierno indígena se les dificultan los procesos formales como las firmas de documentos oficiales, sobre todo los bancarios.

El método de elección es también un tema de reflexión pues se recupera la Asamblea general comunitaria única. En 1950 la "asamblea general comunitaria única” se estableció por primera vez en Oxchuc para elegir a Sebastián López Ch’ijk como su presidente municipal tseltal, ya que antes de esta fecha sólo los mestizos eran elegidos y eran los electores. El método electoral de partidos políticos que aparece desde la institucionalidad del Estado-nación, como un régimen obligatorio, ha sido en todo momento violatorio a los derechos de autodeterminación de los pueblos indígenas.

La fecha señalada para la elección fue el 13 de abril del 2019 en Asamblea general comunitaria única, en la explanada de la cabecera municipal, mediante votación a mano alzada. Lo anterior requería de una logística compleja pues el municipio registró una población total en el año 2018 de 35,780 personas. En esta tarea participaron las autoridades comunitarias para establecer las mesas de registro de sus integrantes, quienes presentaron su credencial de elector y canalizaron el ingreso de sus miembros de forma ordenada. De la misma manera, las policías comunitarias se encargaron de la seguridad de las elecciones. 
Otra situación interesante es que en los requisitos de elegibilidad se cumplió el principio de paridad. La incorporación de las mujeres en todo el proceso es una de las principales innovaciones; sin embargo, lo que se requiere es lograr avances significativos lo que implica modificar la organización social de todo el pueblo de Oxchuc.

Las dificultades que las mujeres enfrentan en Oxchuc para participar como candidatas son mayores, por un lado, los usos y costumbres relacionadas con el tema agrario y por otro las relaciones de parentesco, aunado a que no son consideradas ciudadanas. De lo que resulta que en sentido estricto las mujeres tendrían dificultades para cumplir con un requisito de elegibilidad establecido en las nuevas normas electorales: para poder ser candidato/a se requiere que sea cooperante y que haya servido en la comunidad con servicios conforme a su escalafón comunitario. Por ello la Mesa de debates introdujo una excepción al aclarar que: en el caso de las mujeres que están imposibilitadas para cumplirlo y hayan servido en la comunidad con servicios conforme a su escalafón comunitario serían registradas

En otra sección se establece el principio de revocación del mandato a quien ejerce un cargo municipal, este puede operar por observación libre en cualquier momento del mandato, es decir, por vigilancia ciudadana.

La Asamblea decidió que el próximo presidente municipal y el resto de los integrantes del cabildo estén sujetos a la observación durante su administración, respecto de las causas que se tomen como motivo de separación del cargo.

Cabe mencionar que la norma del modo honesto de vivir no se establece como una posible causa de revocación del mandato; pero quedó incorporada como un requisito de elegibilidad, por lo que ambos principios se cruzan en el derecho consuetudinario electoral de Oxchuc, con la intención de combatir la corrupción que pudiera presentarse.

Se estableció que la Mesa de debates de la Asamblea General sería la encargada de emitir la convocatoria a las elecciones, con base en las normas validadas: conducir la Asamblea de elección desde su instalación hasta su clausura, así como garantizar el libre acceso de la ciudadanía para emitir el voto, además de hacer constar el registro de los asistentes, verificar la votación y sus resultados. 
Las y los candidatos a la Presidencia Municipal fueron postulados por los principales (autoridades tradicionales con prestigio público en Oxchuc) y validados por la Asamblea General, quien revisó el cumplimiento de los requisitos de elegibilidad. El resto de los cargos del ayuntamiento: Síndico/a propietario y suplente y los seis Regidores/as propietarios y suplentes son originarios de 14 localidades diferentes y fueron postulados, por mayoría de las y los representantes de las 120 localidades del municipio de Oxchuc que integran la Asamblea General.

Se acordó que el sábado 13 de abril del 2019 en la explanada de la cabecera municipal de Oxchuc se llevaría acabo mediante la elección, a través de una Asamblea General Comunitaria única, en la que la votación se emitiría a mano alzada. Con esto se materializa el derecho del pueblo de Oxchuc a elegir a sus autoridades municipales bajo su sistema normativo propio, como expresión del derecho a la libre determinación en materia política.

\section{Reflexiones finales}

Se ha demostrado que el derecho electoral indígena y el sistema electoral hegemónico coexisten en Oxchuc de forma tal que la autoridad judicial electoral al resolver un conflicto, armoniza las normas electorales del Estado con los sistemas normativos internos en una especie de interlegalidad.

Las reglas del sistema electoral mexicano al parecer no están funcionando en el contexto de Oxchuc, el resultado del proceso electoral del INE y las resoluciones judiciales del Tepjf no legitiman al que señalan como triunfador o triunfadora, es decir, la ciudadanía oxchuquera no les reconoce como autoridades municipales en sentido material. Para los pueblos indígenas no basta con ganar la elección organizada por sistema electoral hegemónico, es necesario que la autoridad tenga el reconocimiento de la comunidad.

La disputa del gobierno municipal en Oxchuc es una de las expresiones de un tema profundo que es la gobernanza, pues esta resultó seriamente afectada desde la llegada de los partidos políticos y la desaparición del mecanismo de elección en Asamblea. Sin embargo, en el actual contexto político de Oxchuc coexisten el derecho electoral indígena integrado por normas, principios y procedimientos originarios y las reglas del sistema electoral mexicano, esto gracias a la intervención del Tepjf. 
Las ciudadanas y los ciudadanos de Oxchuc se encuentran sometidos a un sistema interno para la elección de autoridades que quizá no coincide con los principios que sustentan los derechos políticos que protege y garantiza el sistema electoral mexicano; pero en la práctica las decisiones de la Asamblea general comunitaria, por ejemplo, han sido más efectivas y plurales que las tomadas por la autoridad electoral hegemónica. Las Asambleas incluyen a representantes de barrios, comunidades y autoridades tradicionales que mediante acuerdos en el ejercicio del poder, durante mucho tiempo lo equilibró y, por tanto, ese mecanismo de elección dio legitimación al triunfador. El que era electo presidente municipal sí representaba a la comunidad y era aceptado como tal.

Pese a ello, al construirse el sistema electoral mexicano lo único que consiguió el Estado fue interferir en el ejercicio de las facultades de las autoridades indígenas, sin reconocerlas como autoridades electorales y sin considerar las particularidades culturales de los pueblos indígenas, que se traducen y reflejan en las decisiones que en cada caso adoptan. Lo anterior suele crear inestabilidad interna y procesos de descomposición del tejido social en los municipios indígenas.

Por otro lado, al incorporarse los derechos colectivos de los pueblos originarios en la Constitución federal (2020) y aparecer en la ley general de medios de impugnación, el juicio para la protección de los derechos políticos del ciudadano, personas y agrupaciones de Oxchuc han promovido ese medio de impugnación, es decir, utilizan la justicia estatal y pretenden refugiarse en ella buscando quizá superponer su voluntad individual sobre la voluntad colectiva.

Aun cuando existen criterios de interpretación del Tepjf aplicables de manera especial en materia electoral indígena, que generalmente flexibilizan el procedimiento, eso no es impedimento para que se pierda de vista la especificidad e identidad cultural y política de la comunidad, pues el aspecto procesal no trasciende al fallo cuando este ignora la resolución o intervención tomada por la autoridad indígena generalmente en Asamblea por contravenir los derechos fundamentales o el orden jurídico.

En México solo mediante la judicialización de los sistemas normativos indígenas es posible ejercer el derecho a la libre determinación en materia política, que la Constitución Política de los Estados Unidos Mexicanos (2020) reconoce a los pueblos originarios. Los conflictos políticos suscitados en Oxchuc- Chiapas en los últimos veinte años que motivaron la promoción de diversos juicios ante el Tepjf hasta que mediante sentencia del Teech se ordenó 
respetar su derecho a elegir bajo sus propios sistemas normativos a sus autoridades municipales. En Oxchuc la autoridad judicial electoral, al resolver un conflicto relacionado con el derecho a la autodeterminación armoniza las normas electorales del Estado con los sistemas normativos internos, mediante criterios de modulación para generar así una especie de interlegalidad. El derecho electoral indígena y el sistema electoral hegemónico coexisten respetando los derechos humanos.

En términos generales, las determinaciones de la Asamblea General de Oxchuc no fueron excluyentes, porque permitieron la participación de todas y todos los miembros de la comunidad con credencial de elector, es decir, hombres y mujeres mayores de 18 años. Las reglas tampoco restringieron la participación política de las mujeres, debido a que se respetó la postulación e integración paritaria en su vertiente vertical. Esto se logró al integrar fórmulas del mismo género para propietarios y suplentes, a fin de cuidar la alternancia del género a partir del cargo de Presidente Municipal.

Tampoco los procesos electivos de asamblea única y bajo el método de mano alzada no se rompió con los principios (Dietz, 2017) democráticos de certeza y seguridad jurídica, en tanto fue posible determinar con precisión el sentido del voto de la mayoría.

Ahora el desafío es que el nuevo gobierno municipal de Oxchuc actúe de forma tal, que este mecanismo de elección se constituya en un modelo a seguir por otros municipios indígenas de Chiapas y de México en general, con base en una administración pública incluyente y con respeto a las diferencias. Si se garantiza lo anterior, es probable que el modelo de elección de Oxchuc se institucionalice 0 , al menos, se continúe el desarrollo de criterios de modulación constitucional como alternativas de pluralismo jurídico. Esto en escenarios en que el desacuerdo político se genera no por la forma de gobierno, pues se decidió conservar la figura del ayuntamiento sino por la corrupción que se vive en el sistema de partidos políticos en tanto alejan cada vez más a la ciudadanía de la participación política.

\section{Referencias bibliográficas}

Anaya, J. (2004). Los derechos de los pueblos indígenas. En F. G. Isa, La protección internacional de los derechos humanos en los albores del siglo XXI (págs. 687-720). Bilbao: Universidad de Deusto. 
Anaya, J. (2011). Aportaciones y avances particulares de los pueblos indígenas de américa a partir de la defensa de sus derechos. REIB Revista Electrónica Iberoamericana, 5(2), 6-9.

Burguete, C. y. (21 de marzo de 2019). 13 de abril de 2019, elecciones por usos y costumbres en Oxchuc. El calendario electoral. Paralelo.

Burguete, C. y. (11 de enero de 2019). Elecciones por usos y costumbres en Oxchuc: los desafíos. Paralelo.

CECH Congreso del Estado de Chiapas. (2 de marzo de 2016). Decreto. Decreto 174. Tuxtla Gutiérrez, Chiapas, México.

CECH Congreso del Estado de Chiapas. (11 de febrero de 2016). Decreto. Decreto 161. Tuxtla Gutiérrez, Chiapas, México.

CECH Congreso del Estado de Chiapas. (23 de enero de 2019). Decreto. Decreto 135. Tuxtla Gutiérrez, Chiapas, México.

CECH Congreso del Estado de Chiapas. (2020). Constitución Política del Estado Libre y Soberano de Chiapas. Constitución Política del Estado Libre y Soberano de Chiapas. Tuxtla Gutiérrez, Chiapas, México.

Cordero, A. d. (2009). Supervivencia de un derecho consuetudinario en el Valle de Tlacolula. Porrúa.

Correas, Ó. (septiembre-diciembre de 1994). Ideología jurídica, Derecho Alternativo y democracia",. Boletín mexicano de Derecho Comparado, XXVII(81), 615-617.

Dietz, G. y. (2011). Educación Intercultural en México, un análisis de los discursos nacionales e internacionales en su impacto en los modelos educativos mexicanos. México: Coordinación de educación intercultural y bilingüe de la Secretaria de educación.

Dietz, G. (2017). Interculturalidad: una aproximación antropológica. Perfiles educativos, 39(156), 23.

Fajardo, S. H. (2010). Resolución de conflictos en comunidades huicholas. En CDI, Sistemas normativos indígenas, huichol, cora tepehuano y mexicanero (pp. 19-58). CDI.

Gómez, M. M. (2004). Tzeltales. CDI-PNUD.

IEEM. (9 de septiembre de 2011). Instituto de Elecciones del Estado de Michoacán. IEEM http://www.iem.org.mx/documentos/Acuerdos/2011/acuerdo_peticion_de_ comunidad_indigena_de_cheran_09_de_septiembre_2011.pdf

IEEM . (2012). Crónica de una decisión histórica en el panorama electoral de Michoacán. Expresiones, 25-27.

IEM Instituto Electoral del Estado de Michoacán. (9 de septiembre de 2011). Acuerdo del Consejo General. CG-38/2001. Morelia, Michoacán, México: IEM.

IEPC Instituto de Elecciones y Participación Ciudadana del estado de Chiapas. (11 de febrero de 2019). Acuerdo General. IEPC/CG-A/007/2019. Tuxtla Gutiérrez, Chiapas, México.

IEPC Instituto de Elecciones y Participación Ciudadana de Chiapas. (15 de junio de 2015). Acuerdo General. IEPC/CG/A-071/2015. Tuxtla Gutiérrez, Chiapas, México: IEPC-Chiapas.

IEPC Instituto de Elecciones y Participación Ciudadana de Chiapas. (10 de febrero de 2017). Acuerdo General. IEPC/CG-005/2017. Tuxtla Gutiérrez, Chiapas, México.

INE. (2016). Estrategia Nacional de Cultura Cívica 2017-2023. INE. 
Korsbaek, L. (1996). Introducción al Sistema de Cargos. Universidad Autónoma del Estado de México.

Ocampo, M. G. (octubre de 2018). Legitimidad de la reincorporación a un cargo público representativo en Chenalhó, Chiapas. Revista de Ciencias Sociales Tlamelaua, (45), 20-29.

Romero, D. E. (2011). Educación Intercultural en México, un análisis de los discursos nacionales e internacionales en su impacto en los modelos educativos mexicanos. SEP-CGEIB.

Santos, B. d. (1987). Law: A Map of Misreading. Toward a Postmodern Conception of Law",. Journal of Law and Society, 1(14), 279-302.

Santos, B. d. (2002). A crítica da razão indolente. Contra o desperdício da experiência (Vol. 1). Porto.

TEECH Tribunal Electoral del Estado de Chiapas. (9 de mayo de 2016). Sentencia. TEECH/ JDC/010/2016. Tuxtla Gutiérrez, Chiapas, México: TEECH.

TEECH tribunal Electoral del Estado de Chiapas. (28 de junio de 2017). Sentencia. TEECH/JDC/019/2017. Tuxtla Gutiérrez, Chiapas, México.

TEPJF. (2017). Guía de actuación para juzgadores en materia de Derecho Electoral Indígena. TEPJF.

TEPJF. (2017). Protocolo para Defensoras y Defensores de los Derechos Político-Electorales de los Pueblos y Comunidades Indígenas. TEPJF.

TEPJF Tribunal Electoral del Poder Judicial de la Federación. (2 de Noviembre de 2011). Sentencia. SUP-JDC-9167/2011. México, México, México: TEPJF.

TEPJF Tribunal Electoral del Poder Judicial de la Federación. (10 de octubre de 2013). Sentencia. SUP-JDC-1011/2013. México, México.

TEPJF Tribunal Electoral del Poder Judicial de la Federación. (17 de agosto de 2016). Sentencia. SUP-JDC-1756/2016. México, México.

TEPJF Tribunal Electoral del Poder Judicial de la Federación. (junio de 2016). Sentencia. SUP-JDC-1697/2016. México, México.

Yrigoyen, F. R. (1999). Pautas de coordinación entre el derecho indígena y el derecho estatal. Fundación Myrna Mack. 